\title{
Karyotype studies on Lycoris radiata populations from China
}

\author{
Y.X. Liu' ${ }^{1}$ Y.H. Zheng ${ }^{1,2}$, T. Xia ${ }^{1}$ and J. Zhou ${ }^{1}$ \\ ${ }^{1}$ Collaborative Innovation Center of Sustainable Forestry in Southern China of \\ Jiangsu Province, College of Biology and the Environment, \\ Nanjing Forestry University, Nanjing, China \\ ${ }^{2}$ Institute of Botany, Jiangsu Province and Chinese Academy of Sciences, \\ Nanjing Botanical Garden, Memorial Sun Yat-sen, Nanjing, China \\ Corresponding author: J. Zhou \\ E-mail: zhiwu@njfu.edu.cn \\ Genet. Mol. Res. 15 (1): gmr.15017357 \\ Received August 4, 2015 \\ Accepted December 7, 2015 \\ Published February 26, 2016 \\ DOI http://dx.doi.org/10.4238/gmr.15017357
}

ABSTRACT. Lycoris radiata is an important medicinal and ornamental plant of China. In the present study, somatic chromosome counts and karyotype analyses, which are important aspects of plant phylogeny and evolution, were performed in 466 individuals from $25 \mathrm{~L}$. radiata populations by root tip squash method. Chromosome counts revealed that 10 populations were diploid $(2 n=2 x=22)$ and 15 were triploid $(2 n=3 x=33)$. Except for one diploid population containing some triploid plants, the remaining 24 populations showed a single cytotype. Karyotype analysis showed that the karyotypes of $L$. radiata varied in different populations and even within the same population. However, based on the Stebbins' system, the karyotype of all the populations could be classified in $4 \mathrm{~A}$ classes. The cluster analysis and ordination methods demonstrated that the $L$. radiata populations grouped in two major clusters. Previous research has shown that the triploid strain of $L$. radiata is a genetically identical species. However, the cluster analysis revealed that the triploid strains clustered in two groups instead of one, which indicates that these strains may not be identical species, genetically. This study is expected to improve the understanding 
of the genetic diversity in $L$. radiata and provide a basis for future studies on species differentiation, speciation, and taxonomy.

Key words: Lycoris radiata; Chromosome number; Karyotype; Ploidy

\section{INTRODUCTION}

Lycoris L. is one of the most important genera of Amaryllis family, most famous for perennial, bulbous plants. This genus consists of approximately 20 species, about 15 of which are endemic to China. It is distributed only in the warm temperate and subtropical zones of East Asia, from southwestern China to southern Korea and Japan, with a few species extending to northern Indo-China and Nepal (Hsu et al., 1994). Since 1928, Lycoris L., with a few, large chromosomes, has been a subject of several cytological and cytogenetic studies (Nishiyama, 1928). The chromosome numbers observed in this genus are: $2 n=12,13,14,15,16,17$, $18,19,21,22,24,25,27,30,32,33$, and 44 corresponding to the diploid, abnormal diploid, triploid, tetraploid, and aneuploid levels, with the basic chromosome number, $x$, being $6,7,8$, and 11 (Shi et al., 2006).

Lycoris radiata Herb., an important member of the genus Lycoris, is widely distributed in China and is well known as the 'Red Spider Lily'. The plant prefers shady and moist areas and can be propagated from small bulbs. These bulbs have been used in traditional Chinese medicine for a long time, due to the presence of two main medicinal components, the lycorine and galantamine, in the bulbs. Furthermore, L. radiata is of great interest to horticulturists because of its scarlet flowers in autumn and green leaves throughout winter.

A perennial medicinal and ornamental herb, naturally occurring $L$. radiata includes diploid, triploid, and tetraploid species (Zhou et al., 2007). Triploid species are completely sterile, having a genomic constitution of $2 n=3 x=33$ (Nishiyama, 1928), whereas diploids are fertile, with a genomic constitution of $2 n=2 x=22$ (Shao et al., 1994). Based on data from our field investigations in China, the completely sterile species are very common and wide spread, but the fertile diploid species are isolated in East China. However, tetraploid species have a narrow distribution and, to the best of our knowledge, are only found in the Huoshan county of Anhui Province (Zhou et al., 2007).

Chromosome number, size, and karyotype are considered good taxonomic characters. Moreover, cytological data are essential in studies focusing on diversification (Stebbins, 1971). It was also reported that the chromosome numbers and karyotypes of some species vary in different populations and even within the same population (Zhou et al., 2007; Fiorin et al., 2013). Several cytological studies have been performed on L. radiata (Nishiyama, 1928; Inariyama, 1932; Kurita, 1987; Sun et al., 1998; Zhou et al., 2007). However, several arguments and problems related to the cytology of $L$. radiata still exist. In addition, such studies have been missing in the large number of investigations on this species in China (Mookerjea, 1955; Shao et al., 1994; Qin et al., 2004; Zhou et al., 2004).

In the present study, the main objective was to investigate the ploidy levels and chromosome numbers in $L$. radiata from 25 different regions and 13 provinces of China. To the best of our knowledge, this is the first study on the ploidy and karyotype patterns in $L$. radiata. The results obtained are expected to provide a basis for future studies on differentiation, speciation, taxonomy, and diversification of $L$. radiata. 


\section{MATERIAL AND METHODS}

\section{Plant material}

Bulbs from 466 accessions representing 25 wild populations of $L$. radiata were collected for use in the study. As this species is extensively propagated clonally, the collected bulbs were from plants spaced 10-30 m apart, a standard interval considering the population size. Each surveyed population represented approximately 8-20 mature individuals. This sampling strategy covered almost the complete geographical range of $L$. radiata in China. All the bulbs were maintained in water until their root tips were harvested for the cytological studies. The names of the populations and details of the accessions, along with the geographic coordinates of the place of their collection, are presented in Table1.Voucher specimens were deposited in the herbarium of the Nanjing Forestry University, Nanjing, China.

Table 1. Geographical data of the collection sites for different $L y c o r i s$ radiata populations.

\begin{tabular}{|c|c|c|c|c|}
\hline Population & Location & Longitude and Latitude & Altitude $(\mathrm{m})$ & Collector and Vouchers \\
\hline L1 & Chizhou city, Anhui Prov. & $117^{\circ} 35^{\prime} \mathrm{E}, 30^{\circ} 19^{\prime} \mathrm{N}$ & 158 & Y.X. Liu \& Y.Q. Zhi; 140301 \\
\hline $\mathrm{L} 2$ & Xiuning county, Anhui Prov. & $118^{\circ} 11^{\prime} \mathrm{E}, 29^{\circ} 39^{\prime} \mathrm{N}$ & 137 & Y.X. Liu \& Y.Q. Zhi; 140302 \\
\hline L3 & Yixian county, Anhui Prov. & $117^{\circ} 48^{\prime} \mathrm{E}, 30^{\circ} 04^{\prime} \mathrm{N}$ & 234 & Y.X. Liu \& Y.Q. Zhi; 140303 \\
\hline L4 & Huainan city, Anhui Prov. & $116^{\circ} 47^{\prime} \mathrm{E}, 32^{\circ} 37^{\prime} \mathrm{N}$ & 118 & Y.X. Liu \& Y.Q. Zhi; 140304 \\
\hline L5 & Maanshan city, Anhui Prov. & $118^{\circ} 27^{\prime} \mathrm{E}, 31^{\circ} 39^{\prime} \mathrm{N}$ & 115 & Y.X. Liu \& Y.Q. Zhi; 140305 \\
\hline L6 & Chuzhou city, Anhui Prov. & $118^{\circ} 16^{\prime} \mathrm{E}, 32^{\circ} 16^{\prime} \mathrm{N}$ & 122 & Y.X. Liu \& Y.Q. Zhi; 140306 \\
\hline L7 & Tongling city, Anhui Prov. & $118^{\circ} 18^{\prime} \mathrm{E}, 32^{\circ} 28^{\prime} \mathrm{N}$ & 27 & Y.Q. Zhi; 140307 \\
\hline L8 & Nanjing city, Jiangsu Prov. & $118^{\circ} 37^{\prime} \mathrm{E}, 32^{\circ} 07^{\prime} \mathrm{N}$ & 248 & Y.X. Liu \& Y.Q. Zhi; 140308 \\
\hline L9 & Lianyungan city, Jiangsu Prov. & $119^{\circ} 24^{\prime} \mathrm{E}, 34^{\circ} 42^{\prime} \mathrm{N}$ & 42 & Y.X. Liu \& Q.R. Zhou; 140309 \\
\hline L10 & Jinyun county, Zhejiang Prov. & $120^{\circ} 18^{\prime} \mathrm{E}, 28^{\circ} 34^{\prime} \mathrm{N}$ & 330 & Y.X. Liu; 140310 \\
\hline L11 & Linan city, Zhejiang Prov. & $119^{\circ} 25^{\prime} \mathrm{E}, 30^{\circ} 20^{\prime} \mathrm{N}$ & 1065 & Y.X. Liu; 140311 \\
\hline L12 & Guixi city, Jiangxi Prov. & $117^{\circ} 15^{\prime} \mathrm{E}, 28^{\circ} 16^{\prime} \mathrm{N}$ & 41 & Y.X. Liu; 140312 \\
\hline L13 & Qianshan county, Jiangxi Prov. & $117^{\circ} 47^{\prime} \mathrm{E}, 27^{\circ} 40^{\prime} \mathrm{N}$ & 282 & Y.X. Liu; 140313 \\
\hline L14 & Ganzhou city, Jiangxi Prov. & $114^{\circ} 54^{\prime} \mathrm{E}, 25^{\circ} 55^{\prime} \mathrm{N}$ & 144 & Z.Y. Liao \& J.L. Dai; 140314 \\
\hline L15 & Longnan county, Jiangxi Prov. & $114^{\circ} 33^{\prime} \mathrm{E}, 24^{\circ} 37^{\prime} \mathrm{N}$ & 390 & M. He; 140315 \\
\hline L16 & Jianou city, Fujian Prov. & $118^{\circ} 08^{\prime} \mathrm{E}, 27^{\circ} 02^{\prime} \mathrm{N}$ & 281 & Y.X. Liu; 140316 \\
\hline L17 & Yanxin county, Hubei Prov. & $115^{\circ} 02^{\prime} \mathrm{E}, 29^{\circ} 42^{\prime} \mathrm{N}$ & 121 & Y.X. Liu; 140317 \\
\hline L18 & Xinning county, Hunan Prov. & $110^{\circ} 51^{\prime} \mathrm{E}, 26^{\circ} 26^{\prime} \mathrm{N}$ & 301 & Y.X. Liu; 140318 \\
\hline L19 & Qingyuan, Guangdong Prov. & $112^{\circ} 46^{\prime} \mathrm{E}, 23^{\circ} 44^{\prime} \mathrm{N}$ & 418 & Y.X. Liu; 140319 \\
\hline $\mathrm{L} 20$ & Duan county, Guangxi Prov. & $108^{\circ} 02^{\prime} \mathrm{E}, 24^{\circ} 06^{\prime} \mathrm{N}$ & 203 & Y.X. Liu; 140320 \\
\hline L21 & Guilin city, Guanxi Prov. & $110^{\circ} 15^{\prime} \mathrm{E}, 25^{\circ} 12^{\prime} \mathrm{N}$ & 196 & Y.X. Liu; 140321 \\
\hline L22 & Xian city, Shanxi Prov. & $108^{\circ} 57^{\prime} \mathrm{E}, 34^{\circ} 12^{\prime} \mathrm{N}$ & 432 & Y.X. Liu \& C.Liu; 140322 \\
\hline L23 & Nanjiang county, Sichuan Prov. & $106^{\circ} 41^{\prime} \mathrm{E}, 32^{\circ} 29^{\prime} \mathrm{N}$ & 1002 & Y.X. Liu; 140323 \\
\hline L24 & Xishui county, Guizhou Prov. & $106^{\circ} 11^{\prime} \mathrm{E}, 28^{\circ} 19^{\prime} \mathrm{N}$ & 1181 & Y.X. Liu; 140324 \\
\hline L25 & Jingdong county, Yunnan Prov. & $100^{\circ} 42^{\prime} \mathrm{E}, 24^{\circ} 36^{\prime} \mathrm{N}$ & 1484 & Y.X. Liu; 140325 \\
\hline
\end{tabular}

\section{Chromosome preparation}

For cytogenetic analysis, the somatic chromosomes in the meristematic cells of the roots tips were used. Firstly, approximately $1-2 \mathrm{~cm}$ long root tips were collected and treated with 0.002 $\mathrm{M}$ 8-hydroxyquinoline for $6 \mathrm{~h}$ at $4^{\circ} \mathrm{C}$. The tips were then fixed in 3:1 absolute ethanol:glacial acetic acid at $4^{\circ} \mathrm{C}$ for a minimum of $24 \mathrm{~h}$. After washing with tap water, the root tips were macerated in $1 \mathrm{M}$ hydrochloric acid at $60^{\circ} \mathrm{C}$ for $6 \mathrm{~min}$, and then stained with phenol-fuchsin for $12 \mathrm{~h}$. Finally, the well stained root tips were toned and tapped in $45 \%$ acetic acid and pressed using a microscope slide (Zhou et al., 2007; Liu et al., 2011). Photomicrographs of chromosomes in the mitotic metaphase were taken with a photomicroscope (Nikon Eclipse 50i, Japan), equipped with a photographic camera (Cool SNAP cf, Photometrics, USA); the images were stored in a computer and processed with Adobe Photoshop, using only those functions that could be evenly applied to the entire image. 


\section{Statistical analyses}

The chromosome counts were determined using at least 20 well-spread metaphase cells for each population. Chromosome measurements were carried out in at least 5 well-spread metaphases for each population. The following parameters were calculated: the absolute $(\mathrm{mm})$ and relative (\%) length of each chromosome pair; the absolute size of the haploid complement $(\mathrm{mm})$, the arm ratio (long arm/short arm) of each chromosome pair, centromeric index, and coefficient of variation in the chromosome size. The karyotype asymmetry index (AsK\%) was calculated using the formula described by Arano and Saito (1980). The karyotype formulae (KF) were determined from the chromosome morphology based on the centromere position in accordance with the classification of Levan et al. (1964) and the karyotype classification was done as described by Stebbins (1971). To group the studied populations by similarity in their karyotypic features, we used the unweighted pair group method with arithmetic mean (UPGMA) clustering, together with ordination based on the principal coordinate analysis (PCoA).

\section{RESULTS}

A total of 466 individuals from 25 populations of $L$. radiata were examined. Chromosome counts revealed that 10 populations were diploid $(2 n=2 x=22)$ and 15 were triploid $(2 n=3 x$ = 33). Except for one diploid population (L14) containing some triploid plants, the remaining 24 populations showed a single cytotype. The tetraploid individuals were not present in any the cytotypes observed. The pictures of the mitotic metaphases and karyograms of the populations are presented in Figure 1. The somatic chromosome numbers (2n), ploidy levels, haploid chromosome length $(\mathrm{HCL})$, AsK\%, symmetry classes of Stebbins, and KF are summarized in Table 2.

Figure 1. Mitotic metaphase chromosomes in the meristematic cells of root tips in L. radiata populations (L1-L25); L7, L12, L14, and L21 populations possessed two karyotypes.

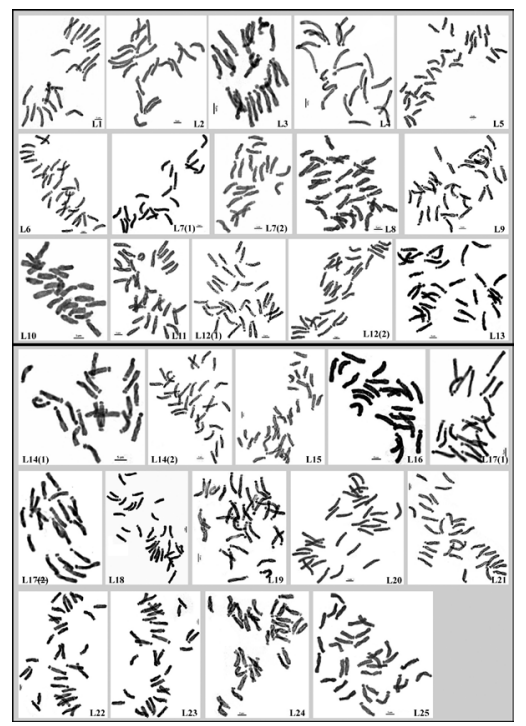

Figure 1. Mitotic metaphase chromosomes in the meristematic cells of root tips in Lycoris radiata populations (L1-L25); L7, L12, L14, and L21 populations possessed two karyotypes. 
Table 2. Karyotypic features in 25 Lycoris radiata populations occurring in China.

\begin{tabular}{|c|c|c|c|c|c|c|c|c|c|c|}
\hline Population & $2 n$ & $\mathrm{PL}$ & $\mathrm{HCL}$ & L/S & $\mathrm{DRL}$ & $\mathrm{Cl}$ & $\mathrm{CV}$ & AsK\% & SC & $\mathrm{KF}$ \\
\hline $\mathrm{L} 1$ & 22 & $2 x$ & 155.47 & 1.53 & 3.94 & 10.49 & 11.44 & 89.56 & $4 \mathrm{~A}$ & $4 s t+18 t(2 S A T)$ \\
\hline L2 & 22 & $2 x$ & 154.38 & 1.70 & 4.93 & 11.05 & 14.33 & 88.99 & $4 \mathrm{~A}$ & $4 s t+18 t$ \\
\hline L3 & 22 & $2 x$ & 150.71 & 1.30 & 2.38 & 11.79 & 9.28 & 88.16 & $4 \mathrm{~A}$ & $4 s t+18 t$ \\
\hline L4 & 22 & $2 x$ & 156.39 & 1.77 & 5.29 & 10.71 & 17.70 & 89.27 & $4 \mathrm{~A}$ & $2 s t+20 t$ \\
\hline L5 & 33 & $3 x$ & 114.06 & 1.39 & 2.91 & 12.07 & 10.88 & 87.98 & $4 \mathrm{~A}$ & $9 s t+24 t$ \\
\hline L6 & 33 & $3 x$ & 129.41 & 1.44 & 3.33 & 11.80 & 10.87 & 88.22 & $4 \mathrm{~A}$ & $9 s t+24 t$ \\
\hline L7 & 22 & $2 x$ & 134.32 & 1.32 & 2.54 & 13.32 & 9.35 & 86.72 & $4 \mathrm{~A}$ & $10 s t+12 t, 12 s t+10 t$ \\
\hline L8 & 33 & $3 x$ & 121.25 & 1.44 & 3.25 & 12.16 & 10.44 & 87.90 & $4 \mathrm{~A}$ & $9 s t+24 t$ \\
\hline L9 & 33 & $3 x$ & 124.66 & 1.29 & 2.36 & 11.61 & 9.83 & 88.40 & $4 \mathrm{~A}$ & $15 s t+18 t$ \\
\hline L10 & 22 & $2 x$ & 116.86 & 1.31 & 2.43 & 13.44 & 9.25 & 86.60 & $4 \mathrm{~A}$ & $10 s t+12 t$ \\
\hline L11 & 33 & $3 x$ & 115.06 & 1.59 & 4.35 & 12.53 & 13.06 & 87.49 & $4 \mathrm{~A}$ & $9 s t+24 t$ \\
\hline L12 & 33 & $3 x$ & 123.37 & 1.58 & 4.30 & 10.87 & 13.64 & 89.12 & $4 \mathrm{~A}$ & $6 s t+27 t, 33 t$ \\
\hline L13 & 33 & $3 x$ & 131.44 & 1.50 & 3.77 & 10.43 & 11.23 & 89.57 & $4 \mathrm{~A}$ & $6 s t+27 t$ \\
\hline L14 & 22,33 & $2 x, 3 x$ & 116.52 & 1.41 & 3.10 & 11.70 & 10.65 & 88.32 & $4 \mathrm{~A}$ & $10 s t+12 t, 33 t$ \\
\hline L15 & 33 & $3 x$ & 113.88 & 1.68 & 4.81 & 14.54 & 15.90 & 88.97 & $4 \mathrm{~A}$ & $6 s t+27 t$ \\
\hline L16 & 22 & $2 x$ & 140.63 & 1.63 & 4.52 & 11.37 & 13.82 & 88.69 & $4 \mathrm{~A}$ & $8 s t+14 t$ \\
\hline L17 & 22 & $2 x$ & 158.02 & 1.71 & 4.92 & 11.29 & 15.60 & 88.82 & $4 \mathrm{~A}$ & $8 s t+14 t, 10 s t+12 t$ \\
\hline L18 & 33 & $3 x$ & 112.73 & 1.51 & 3.81 & 11.58 & 12.98 & 88.41 & $4 \mathrm{~A}$ & $6 s t+27 t$ \\
\hline L19 & 33 & $3 x$ & 149.11 & 1.71 & 5.00 & 10.05 & 15.31 & 90.01 & $4 \mathrm{~A}$ & $33 t$ \\
\hline L20 & 33 & $3 x$ & 145.21 & 1.51 & 3.78 & 10.36 & 11.37 & 89.62 & $4 \mathrm{~A}$ & $33 t$ \\
\hline L21 & 33 & $3 x$ & 134.36 & 1.60 & 4.39 & 10.77 & 13.26 & 89.31 & $4 \mathrm{~A}$ & $6 s t+27 t$ \\
\hline L22 & 33 & $3 x$ & 148.66 & 1.71 & 4.76 & 12.06 & 15.72 & 87.98 & $4 \mathrm{~A}$ & $15 s t+18 t$ \\
\hline L23 & 33 & $3 x$ & 114.54 & 1.30 & 2.36 & 12.34 & 10 & 87.66 & $4 \mathrm{~A}$ & $12 s t+21 t$ \\
\hline L24 & 33 & $3 x$ & 115.99 & 1.40 & 2.99 & 11.92 & 10 & 88.09 & $4 \mathrm{~A}$ & $9 s t+24 t$ \\
\hline L25 & 33 & $3 x$ & 121.02 & 1.39 & 2.82 & 10.82 & 11 & 89.17 & $4 \mathrm{~A}$ & $3 s t+30 t$ \\
\hline
\end{tabular}

$2 \mathrm{n}=$ somatic chromosome number; $\mathrm{PL}=$ ploidy levels; $\mathrm{HCL}=$ haploid chromosome length; L/S = longest/shortest chromosome ratio; $\mathrm{DRL}=$ difference of relative length range; $\mathrm{Cl}=$ centromeric index; $\mathrm{CV}=$ coefficient of variation; AsK\% = karyotype asymmetry index; SC = symmetry classes; KF = karyotype formula; subterminal-centromeric(st), terminal-centromeric $(\mathrm{t})$.

Among all the populations of $L$. radiata, $\mathrm{HCL}$ was highest $(158.02 \mathrm{~mm})$ in the Yanxin population (L17), which was diploid with $2 n=22$, whereas it was lowest $(112.73 \mathrm{~mm})$ in the Xinning population (L18), which was triploid with $2 n=33$. Most of the triploid populations had relatively higher HCL in comparison to the triploid populations. Among the populations studied, L4 possessed the highest CV (17.70) indicating the highest variation among its chromosomes compared to the other $L$. radiata populations, whereas L10 possessed the lowest value (9.25). These populations also varied in their KF (Table 2). The chromosomes were mostly telocentric and subterminal, except in two populations (L19 and L20) that possessed only telocentric chromosomes. Compared to the other populations, L1 had one pair of satellite chromosomes. However, some populations possessed the same KF. For example, the KF of L1, L2, and L3 populations were 4st+18t; those of L5, L6, L8, L11, and L24 were 9st+24t, of L13, L15, L18, and L21 were 6st+27t; of L9, L22 were 15st+18t; L19, and of L20 were 33t. However, different cytotypes were found in the same population, such as L7, L12, L14, and L17. The AsK \% varied from 86.60 (in the diploid population, $\mathrm{L} 10$ ) to 90.01 (in the triploid population, L19).

Analysis of the chromosome constitution in the $25 \mathrm{~L}$. radiata populations revealed that the arm ratios of the 25 pairs of chromosomes, both in the diploid and triploids, exceeded 2.0, indicating a very high intrachromosomal asymmetry. However, the ratio of longest to the shortest chromosome was $<2$. Both the above-mentioned characteristics classified the karyotype of all the diploid and triploid populations as 4A (Stebbins, 1971; Table 2).

The UPGMA clustering of the species based on the karyotype data produced two major clusters (Figure 2). The first major cluster I comprised of two sub-clusters: one composed of 
eight triploid populations (L12, L19, L25, L20, L21, L15, L18, and L13) together with three diploid populations ( $L 1, L 2$, and L3) and the other composed only of the diploid population $L 4$. The second cluster II also comprised of two sub-clusters: one composed of two diploid populations (L7 and L10) and the other composed of eight triploid populations (L9, L22, L24, L5, L23, L6, L8, and L11) together with three diploid populations (L14, L16, L17), all in close proximity to each other.

The PCoA analysis, performed to visualize the displacement of the populations, revealed that the first three principle coordinates based on Eigen values accounted for $99.96 \%$ of the total variations among all the populations studied. The first (PCoA 1), second (PCoA2), and third (PCoA3) principal components accounted for 98.36, 0.96, and $0.64 \%$ of the total variance. The bi-plot, created on the basis of the first two PCoAs (99.32\% of the total variability), supported the clustering pattern of the UPGMA dendrogram, which also divided the studied populations into two main clusters: Groups I and II (Figure 3). The PCoA provided a better graphical illustration and a clear separation of the $L$. radiata populations.

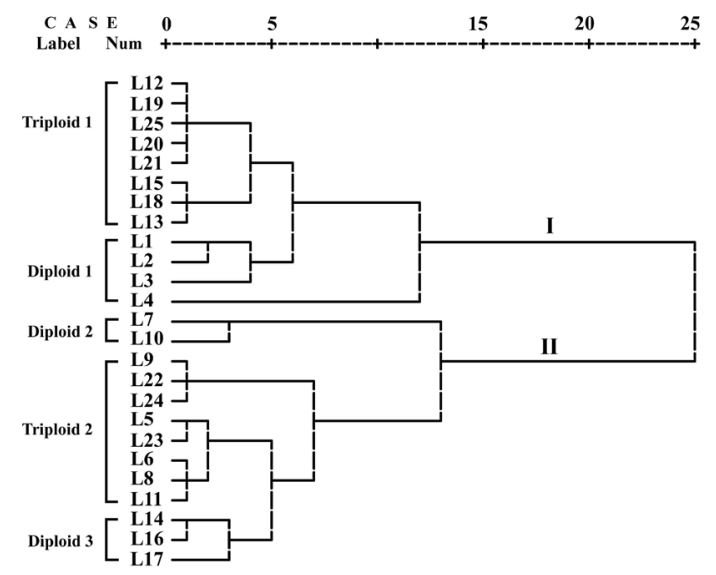

Figure 2. UPGMA cluster analysis of 25 Lycoris radiata populations.

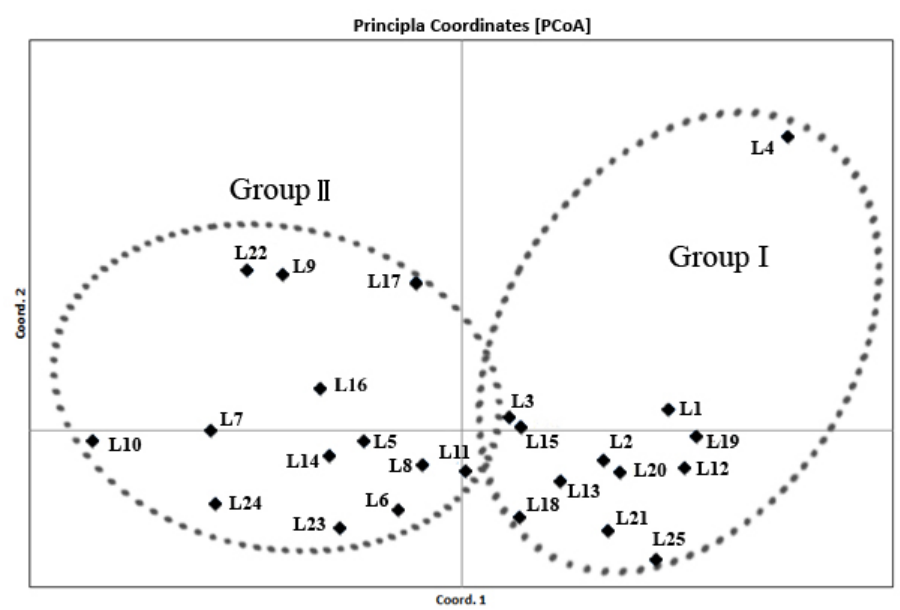

Figure 3. Principal coordinates analysis of 25 Lycoris radiata populations. 


\section{DISCUSSION}

Several cytological studies conducted on $L$. radiata, worldwide, have revealed that $L$. radiata is a complex species that can be diploid $(2 n=2 x=22)$ or triploid $(2 n=3 x=33$; Takemura, 1962; Chen and Li, 1985; Kurita, 1989; Sun et al., 1998). The basic chromosome number, $x$, of $L$. radiata is 11 . This completely sterile species is very common and wide spread in China. However, according to our field observations, the fertile species is isolated, in the East China region. Zhou et al. (2007) reported a tetraploid cytotype of $L$. radiata for the first time; they observed that in these strains, the tepals did not recurve and the margins did not undulate, characteristics very distinct from those of the diploids and triploids. However, the discovery of the new tetraploid cytotype raised some questions. In our extensive field investigations, we did not find the species with the tetraploid cytotype, probably because of the small range of distribution of the tetraploids.

The usual karyotype of $L$. radiata consists only of rod-shaped chromosomes with subterminal and terminal constriction (with only one arm). However, several studies have shown some abnormal karyotypes of $L$. radiata, such as $2 \mathrm{n}=33=1 \mathrm{~m}+31 \mathrm{t}+1 \mathrm{~B}, 2 \mathrm{n}=32=1 \mathrm{~m}+31 \mathrm{t}$ (Bose, 1963; Kurita, 1988); $2 \mathrm{n}=22=4 \mathrm{st}+18 \mathrm{t}$ (Chen and Li, 1985; Sun et al.,1998); $2 \mathrm{n}=23=$ $6 s t+14 t+2 T+1 B, 2 n=22=1 m+12 s t+8 t+1 B($ Shao et al., 1994); $2 n=24=6 m+8 s m+6 s t$ $+4 \mathrm{t}$ (Qin et al., 2004); $2 \mathrm{n}=21=1 \mathrm{~m}+6 \mathrm{st}+4 \mathrm{t}+9 \mathrm{~T}+1 \mathrm{~B}, 2 \mathrm{n}=21=1 \mathrm{M}+10 \mathrm{st}+9 \mathrm{~T}+1 \mathrm{~B}$ (Zhou et al., 2004); $2 \mathrm{n}=21=1 \mathrm{~m}+20 \mathrm{st}, 2 \mathrm{n}=25=1 \mathrm{~m}+20 \mathrm{st}+2 \mathrm{t}+2 \mathrm{~T}$ (Zhou et al., 2007). In addition, Qin et al. (2004) observed long oval chromosomes. The karyotypes observed in our studies were different from those reported previously. The present data document the most extensive karyotypes known to date for $L$. radiata, with 11 karyotypes (Table 2) and different cytotypes observed in the same population. On the basis of previously reported results and those present in this study, it can, therefore, be concluded that the chromosome numbers and karyotypes of $L$. radiata vary in different populations.

Mookerjea (1955) observed that the karyotypes of $L$. radiata were very variable, and also consisted of satellite chromosomes; because the author could not explain the great variability in the karyotypes of $L$. radiata, the opinions expressed could not gain sufficient attention at that time. Based on the results from our studies on the $25 \mathrm{~L}$. radiata populations, we concur with the observations of Mookerjea (1955) that the karyotypes in L. radiata show great variability among different populations and even within the same population. In addition, we observed the satellite chromosomes in the L1 population, confirming the results of Mookerjea (1955).

Polyploidy, defined as the possession of at least three complete set of chromosomes, is a widespread phenomenon in the flowering plants. It occurs in $30-35 \%$ of the angiosperms, according to Stebbins (1971), whereas Coghlan et al. (2005) estimated that $50-70 \%$ of all the species could be polyploid. Polyploidy has significant effects on the biochemistry, ecophysiology, and morphology of plants (Balao et al., 2009). Of the 25 populations surveyed, 15 were triploids. Clearly, polyploidy is prevalent in L. radiata. However, in the present study, except for one diploid population containing some triploid plants, the remaining populations had a single cytotype. This indicates an effect of minority cytotype exclusion and/or a widespread lack of gene-flow between the ploidy levels in nature. Balao et al. (2009) used sample chromosome counts and flow cytometry to determine the overall genome size and the ploidy levels in 244 individuals belonging to 25 populations of Dianthus broteri. Extensive variation in chromosomes numbers (four levels of ploidy) was detected with each population reported to have a single ploidy level. Hardy et al. (2001) and Husband and Sabara (2004) also reported that Centaurea jacea and Chamerion angustifolium plants, which possessed different ploidy levels, were effectively isolated, reproductively. Levin (1975) reported 
that cytological races within a polyploid species could be spatially/ecologically segregated, which was explained on the basis of minority cytotype exclusion or the varying ecological tolerances (Mandáková and Münzbergová, 2006).

The possible origin of the triploid strains of $L$. radiata remains debatable and has attracted the attention of many researchers. Allozyme analysis by Chung (1999) in eight Korean populations of the sterile triploid revealed that all the 24 allozyme loci surveyed were monomorphic in all the populations. He suggested that only a few bulbs of $L$. radiata were introduced from China, and secondarily, from Japan and Korea, and they were naturalized in the South Korean peninsula via a strong vegetative reproduction by the rapid formation of new bulbs. These results suggested that there were few genetic variations among the triploid strains in Japan and Korea and that they might have evolved from a common ancestor introduced from China. In addition, Hayashi et al. (2005) also reported that an unidentified triploid could be the mother clone of all the triploid strains in Japan. Inter-simple sequence repeat markers analysis by Lv (2006) conducted in a few species of Lycoris indicated that no special bands were amplified in the different triploid populations. They suggested that the triploid Lycoris species was highly identical, genetically. Our results demonstrate that the triploid strains, which were distinctly divided into two parts (Triploid 1 and Triploid 2; Figure 2), indicate that the strains of $L$. radiata showed a genetic differentiation and may not be a highly identical species, genetically. The two groups of triploid strains might have originated from different diploid strains of L. radiata. Whether the triploids were derived from different diploids or not, is a question that needs further investigation using allozyme, molecular, and in situ hybridization methods.

\section{Conflicts of interest}

The authors declare no conflict of interest.

\section{ACKNOWLEDGMENTS}

Research supported by the Public Welfare Forest Project (\#201004056), the Innovation Project of Jiangsu Postgraduate Education (\#KYZZ0247), and the Priority Academic Program Development of Jiangsu High Education Institutions (\#PAPD) and North Jiangsu Science and Technology Development Projects (\#BN 2013065).

\section{REFERENCES}

Arano $\mathrm{H}$ and Saito $\mathrm{H}$ (1980). Cytological studies in family Umbelliferae, 5: Karyotypes of seven species in subtribeSeselinae. La Kromosomo 2: 471-480.

Balao F, Casimiro-Soriguer R, Talavera M, Herrera J, et al. (2009). Distribution and diversity of cytotypes in Dianthus broteri as evidenced by genome size variations. Ann. Bot. (Lond.) 104: 965-973. http://dx.doi.org/10.1093/aob/mcp182

Bose S (1963). A new chromosome number and karyotype in L. radiata. Nature 197: 1229-1230. http://dx.doi. org/10.1038/1971229b0

Chen YH and Li MC (1985). Karyotype analysis of four species (varieties) of Lycoris Herb. Acta Hort. Sin. 12: 57-60.

Chung MG (1999). Notes on allozyme variation in Lycoris radiata (Amaryllidaceae) from Korea. Bot. Bull. Acad. Sin. 40: $227-230$.

Coghlan A, Eichler EE, Oliver SG, Paterson AH, et al. (2005). Chromosome evolution in eukaryotes: a multi-kingdom perspective. Trends Genet. 21: 673-682. http://dx.doi.org/10.1016/j.tig.2005.09.009

Fiorin FG, Ruas PM, Ortiz MA, Urtubey E, et al. (2013). Karyotype studies on populations of two Hypochaeris species (H. catharinensis and H. lutea), Asteraceae, endemics to southern Brazil. Genet. Mol. Res. 12: 1849-1858. http://dx.doi. org/10.4238/2013.January.4.4

Hardy OJ, de Loose M, Vekemans X and Meerts P (2001). Allozyme segregation and inter-cytotype reproductive barriers in the polyploid complex Centaurea jacea. Heredity (Edinb) 87: 136-145. http://dx.doi.org/10.1046/j.1365-2540.2001.00862.x 
Hayashi A, Saito T, Mukai Y, Kurita S, et al. (2005). Genetic variations in Lycoris radiata var. radiata in Japan. Genes Genet. Syst. 80: 199-212. http://dx.doi.org/10.1266/ggs.80.199

Hsu PS, Kurita S, Yu ZZ and Lin JZ (1994). Synopsis of the genus Lycoris (Amaryllidaceae). SIDA 16: $301-331$.

Husband BC and Sabara HA (2004). Reproductive isolation between autotetraploids and their diploid progenitors in fireweed, Chamerion angustifolium (Onagraceae). New Phytol. 161: 703-713. http://dx.doi.org/10.1046/j.1469-8137.2004.00998.x

Inariyama S (1932). Cytological studies in the genus Lycoris I. Conjugation of chromosomes in meiosis of $L$. albifloraKoidz. Bot. Mag. Tokyo 46: 426-434. http://dx.doi.org/10.15281/jplantres1887.46.426

Kurita S (1987). Variation and evolution in the karyotype of Lycoris, Amaryllidaceae. IV Intraspecific variation in the karyotype of L. radiata (L'Herit.) Herb. and the origin of this triploid species. Cytologia (Tokyo) 52: 137-149. http://dx.doi.org/10.1508/ cytologia.52.137

Kurita S (1988). Variation and evolution in the karyotype of Lycoris, Amaryllidaceae VI. Intrapopulational and/or intraspecific variation in the karyotype of L. sanguinea Max. var. kiushiana and L. sanguinea Max.var. koreana (Nakai) Koyama. Cytologia (Tokyo) 53: 307-321. http://dx.doi.org/10.1508/cytologia.53.307

Kurita S (1989). Variation and evolution in the karyotype of Lycoris, (Amaryllidaceae) V. Chromosomal variation in L. sanguinea Maxim. Plant Species Biol. 4: 47-60. http://dx.doi.org/10.1111/j.1442-1984.1989.tb00047.x

Levan A, Fredga K and Sandberg AA (1964). Nomenclature for centromeric position on chromosome. Hereditas 52: $201-220$. http://dx.doi.org/10.1111/j.1601-5223.1964.tb01953.x

Levin DA (1975). Minority cytotype exclusion in local plant populations. Taxon 24: 35-43. http://dx.doi.org/10.2307/1218997

Liu K, Zhou SB, Wang Y and Zhang D (2011). A karyomorphological study on two newly recorded taxa of Lycoris (Amaryllidaceae) in Anhui province. Caryologia 64: 158-163. http://dx.doi.org/10.1080/00087114.2002.10589778

LV YH (2006). The tissue culture and ISSR analysis of biological diversity about Lycoris sps. Master's thesis, Sichuan University Press, Cheng Du.

Mandáková T and Münzbergová Z (2006). Distribution and ecology of cytotypes of the Aster amellus aggregates in the Czech Republic. Ann. Bot. (Lond.) 98: 845-856. http://dx.doi.org/10.1093/aob/mcl165

Mookerjea A (1955). Cytology of Amaryllids as an aid to the understandings of evolution. Caryologia 7: 1-71. http://dx.doi.org/ 10.1080/00087114.1955.10797483

Nishiyama I (1928). Reduction division in Lycoris. Bot. Mag. Tokyo 42: 509-513. http://dx.doi.org/10.15281/jplantres1887.42.509

Qin WH, Zhou SB and Wang HY (2004). A new chromosome number and karyotype in Lycoris radiata in Anhui Province. Guihaia 24: 29-32.

Shao JZ, Yang JG, Zhang DC and Nie LW (1994). The discovery of diploid Lycoris radiata (L'Her.) Herb. from AnHui. ActaPhytotaxon. Sin. 32: 549-552.

Shi S, Qiu Y, Li E, Wu L, et al. (2006). Phylogenetic relationships and possible hybrid origin of Lycoris species (Amaryllidaceae) revealed by its sequences. Biochem. Genet. 44: 198-208. http://dx.doi.org/10.1007/s10528-006-9023-4

Stebbins GL (1971). Chromosomal evolution in higher plants. Edward Arnold, London.

Sun YG, Zheng Y, Zhang DC and Shao JZ (1998). Karyotype studies of 4 species of Lycoris from Anhui. Guihaia 18: $363-367$.

Takemura E (1962). Morphological and cytological studies on artificial hybrids in the genus Lycoris II. Artificial hybrids among the different species having only rod-shaped chromosomes. Bot. Mag. Tokyo 75: 72-79. http://dx.doi.org/10.15281/ jplantres1887.75.72

Zhou SB, Qin WH, Yu BQ, Cui Y, et al. (2004). Karyotype studies on Lycoris radiata from two populations in Anhui Province. Acta Bot. Yunnanica 26: 421-426.

Zhou SB, Yu BQ, Luo Q, Hu JR, et al. (2007). Karyotype of six populations of Lycoris radiata and discovery of the tetraploid. ActaPhytotaxon. Sin. 45: 513-522. 